\title{
WRITING A RESEARCH PAPER: A GUIDE
}

\author{
Laxmi Shrestha, ${ }^{1}$ Bishal Joshi, ${ }^{2}$ Anand Kumar
}

\section{ABSTRACT}

\section{INTRODUCTION}

A research paper is a part of academic writing where there is a gathering of information from different sources. It is multistep process. Selection of title is the most important part of research writing. The title which is interesting should be chosen for the research purpose. All the related information is gathered and the title for research is synthesized. After thorough understanding and developing the title, the preliminary outline is made which maintains the logical path for its exploration. After preliminary research, proper research work is started with collection of previous resources which is then organized and important points are noted. Then research paper is written by referring to outlines, notes, articles, journals and books. The research paper should be well structured containing core parts like introduction, material and methods, results and disscussion and important additional parts like title, abstract, references.

\section{KEYWORDS}

Academic writing, Preliminary research, Research paper.

1. Department of Pharmacology, Universal College of Medical Sciences, Bhairahawa, Nepal

2. Department of Physiology, Universal College of Medical Sciences, Bhairahawa, Nepal

3. Department of Surgery, Universal College of Medical Sciences, Bhairahawa, Nepal

DOI: http//doi.org/10.3126/jucms.v9i01.37987

For Correspondence

Dr Laxmi Shrestha

Department of Pharmacology

Universal College of Medical Sciences

Bhirahawa, Nepal

Email: drshresthalaxmi@gmail.com 


\section{INTRODUCTION}

A research paper is a part of academic writing where there is a gathering of information from different sources. It is based on author's original research on particular topic, collection of expert ideas together, own ideas or conclusion supported by expert opinion, evidence, data analysis and interpretation of the research findings. ${ }^{1}$ There are two different types of research paper: primary research and secondary research. The primary research is the study of a subject through first hand investigation, such as analyzing a literary or historical text, a film, a performance, conducting a survey or an interview, carrying out a laboratory experiment. Primary sources include statistical data, historical documents, and works of literature or art. Secondary research is the examination of studies that other researchers have made on a subject. Examples of secondary sources are articles and books, scientific debates, or literary works. ${ }^{2}$

Writing a research paper is making contribution to the scientific community. In order for the results of research to be accessible to other professionals and have a potential effect on the scientific community, it must be written and published in suitable journals. Mostly the scientific discovery is published in peer reviewed journals. ${ }^{3}$ For publishing a research results, there should be some results that worth reporting, contribute in the progress of scientific community and that reaches a broader audience. ${ }^{4}$

\subsection{Selecting a title}

Title selection is very important steps for writing a research paper. Preliminary research on various topics is done before the selection of a title. Then the title for the research is refined and chosen. The title which is interesting and one would like to work on it, should be chosen for the research purpose. A good research paper should address a specific research question. A good research question should have specificity, originality, and novelty. It should be precise and relevant to scientific community. ${ }^{5}$ The following points can be considered while choosing a title for research purpose:

- Interest in a particular title

- Time frame in which particular title can be covered

- Availability of enough resources

- Title within the scope

- Address the research question

- Relevance

\subsection{Understanding the title}

Once the title is decided, it is important to have some background reading to gain an understanding of the subject area. Exploring the knowledge about the topic will help to develop a core title. The title should be refined so that it is not wide in scope and all the information can be covered. The following resources can be used to understand the title:

- Chapters in textbook, dictionaries and other specialized reference books

- Encyclopedia (internet sources), web pages

- Research articles, scholarly journals

- Magazine or newspaper articles

While preparing this background, one should make notes that defines the title which will be useful for research. ${ }^{6}$

\subsection{Developing the title}

Title is the most important part of research paper. It attracts the readers. Therefore, while collecting materials for the title, one should think, develop and explore ideas in the paper. Ideas are the key of the title which will be helpful in the research. It should be clear and interesting. Finding out more about the subject will help to create a good research paper. Ask a question like why, who, what, where, when, how? so that it will be easy to collect information for the research work. Make a system for noting sources, taking notes and organizing materials according to its relative importance. The author's name and affiliation are mentioned in the title page.

\subsection{Preliminary outline}

Once the title is established, one should be ready for creating preliminary outline for the research paper. The outline is similar to template for your research. It forms a structure of your paper and helps to generate ideas and formulate hypothesis. ${ }^{7}$ It is necessary to explore research materials by reading reference books, periodicals, internet articles etc. The researcher should read review articles in the particular field of interest before deciding to research on particular subject. The researcher should find out the research question and also should find the gap present in the article that has not been answered in existing studies or research within the field so that it can be done in his/her research article. During this process, one should pay close attention for quality of reference materials used. For example, if the research paper is related to health, the search should be in medical journals and books rather than searching in general magazine or newspaper. The preliminary outline should not be regarded as waste of time. The materials found during this preliminary outline will be helpful for the research paper. The outline is the guide for the content of research paper. It will help to maintain logical path for the exploration of the title. The outline allows breaking the subject into manageable sections. Thus, it helps to keep the point and avoid omitting the key sections from the research paper.

The followings are the content of preliminary outline. ${ }^{8}$

\section{a) Heading}

It contains the title of the research. It should be concise but informative, containing the key words of the paper. It should be short and should adequately describe the research work. 


\section{b) Introduction}

It is the clear statement of a problem of a research and the reason of studying it. In this section, the author should explain the aims and objective of the study clearly. The problems should be introduced in the first few lines. It should give the concise and appropriate background for the discussion of problems in research work. It should also mention its significance, scope of the research work. It should follow inverted funnel approach. Initially, the introduction should describe the general information then awareness and attitudes related to particular issues and finally it should be specific to targeted objective of the research and should also provide constructive suggestions for improvement of the research paper.

\section{c) Body}

It contains support or proof of the article. It mainly consists of materials and methods and results.

\section{d) Conclusion}

It includes summing up results, mentioning the aspects that were not addressed in more detail, or pointing the way for further research.

The preliminary outline helps to produce following:

- Finding more interesting similar topics

- Relevant material

- Availability of research material

- Narrowing of title in case of excess information

- Avoid difficulty in understanding and starting research work.

\section{RESEARCH WORK}

After completion of preliminary search, the research work is started. The materials like books, journals, articles etc. are required for research work. The published materials in related field should be searched. The materials should be properly read, evaluated and analyzed and referenced accordingly.

After collecting the information and knowledge about the title, revision of preliminary outline should be done. During the research work, one may come across the materials that support or may oppose the title. The material which opposes the title should not be ignored. Both types of materials may be useful during the research work.

While writing a research paper one should follow the research ethics. Before conducting any research work, ethical clearance should be taken. The researcher should adhere to ethical principles in order to protect the dignity, rights and welfare of the research participants.

\section{a. Collecting resources}

Collecting resources is important for writing a research paper.
Resources like books, articles, journals, documents or website from where the related information can be obtained may not be sufficient or useful. Evaluation of resources to determine the appropriate argument for research paper is necessary. The scholarly resources and combination of other resources are important for writing research articles. ${ }^{6}$

- To determine if a book is useful

- Scan the table of contents to determine the topics it covers

- Check the index at the back of the book for keywords that describe the title

- Scan the chapters that pertain to the title

- Read through the introduction of the book to get an idea of what it covers

- To determine if a periodical article is useful

- Read the abstract (summary) of the article

- If there is no abstract, read the first paragraph and conclusion of the article

- Review charts, tables, footnotes, references

- To determine if a web site is useful

- To what depth of the topic is explored

- The qualifications of the author or page editor should be determined

- The reliability of the information should be checked.

- The accessibility of website should be checked

\section{b. Organizing resources}

It is very important to organize the resources and find the research paper. One should organize the resource by taking notes, downloading articles or by sending emails. It is essential to note every book, article, document or web sites when researching and writing the research paper. It is important to record the following information:

\section{BOOK}

- Author name (last name, first name)

- The full title of the book (underlined or in italics)

- Place of publication (usually found on the title page or the back of the title page)

- Publisher

- Date of publication

\section{Periodical article}

- Author name (last name, first name)

- Title of the article

- Name of the journal or magazine (underlined or in italics)

- Volume number and issue number (if there is one)

- Date/Year of publication

- Page numbers of the article

\section{Web site}

- Author or person(s) responsible for the intellectual content of the page (if available)

- Title of page (underlined or in italics) 
- Date of last update of page, if available

- Place or location of page, if available

- Date the data is retrieved/viewed from the page

- URL

\section{c. Plagiarism}

While doing research, various articles, journals, books and newspapers are referred in order to collect the related information. Research paper is made through these collected materials. In today's world, internet is making it easy to download and copy the materials. The most important protocol of academic writing is the principle of giving credit to the work of others. "Plagiarism is defined as the act of claiming the words or ideas of another person as your own". Plagiarisms is a serious violation of the ethical standards of academic writing.

The plagiarism is of two types: a) intentional plagiarism b) unintentional plagiarism.

\section{a) Intentional plagiarism:}

One type of intentional plagiarism is knowingly copying the whole passage from outside sources into one's work without documentation. Another is buying research papers from online sources or friends. These intentional acts of academic dishonesty are the forms of plagiarism.

b) Unintentional plagiarism is also the violation of academic integrity.

\section{Plagiarism is:}

- Using copied material without enclosing that material in quotation marks and without appropriately acknowledging its source.

- Paraphrasing or summarizing too close to the original wording.

- Submitting work that has been written in full or in part by someone else.

- Borrowing, selling, purchasing, or lending academic work for submission for academic credit.

So while writing research paper, one should provide a citation and use quotation marks to show exactly from where the information is taken. ${ }^{9}$

\section{TAKING NOTES}

Taking notes is an important part of research writing. Once the data is collected and resources are organized, it is essential to search and determine the important ones useful for the research paper. If the collected resources have appropriate information related to the research work, it should be carefully read and notes of important points should be made. For taking notes, one should develop their own methods. It is important to make a clear difference between their own thoughts and those derived from other sources. It should be grouped and organized together. The materials or resources should be read carefully and summarized. During research paper writing, the notes should be carefully reviewed to ensure that the paper is within the guideline of the article.

Consider the following point when taking notes: ${ }^{6}$

- Ideas that describe the issue

- Title of research

- Ideas that support or refuse the paper

- Factual or statistical information that enhance the argument

- Quotations from another's work that support the argument

\section{WRITING THE DRAFT/ RESEARCH PAPER}

After completion of all work, one is ready to write the research paper by referring the outline, notes, articles, journals and books. The collected resources can be used properly for writing the research paper. During the process of writing, one may require modifications at some parts of research paper. The quotes should be judiciously used from primary or secondary literature to clarify all the important points. If there is any problem with certain section while writing the paper, a section can be skipped or a space can be left where quotation can be used to support the agreement.

The structure of research paper comprises three core parts, namely Introduction, Body (methods and results) and Discussion. Basic structure of typical research paper is in the sequence of Introduction, Material and methods, Results and Discussion (IMRD). The progression of the thematic scope of a paper within these parts typically follows a pattern called the 'Hourglass Model' (Figure 1, light-grey parts; cf. Swales, 1993). However, there are additional parts of research paper which is very important. These are Title, Abstract, References. The "King Model" is the extension of "Hourglass Model" indicated by dark grey color in figure 2 .

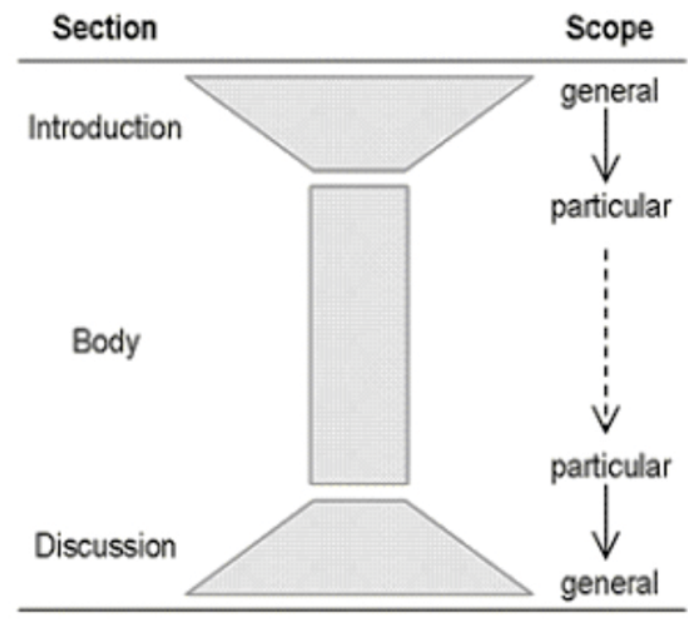

Figure 1. The 'Hourglass Model' (light-grey parts) 


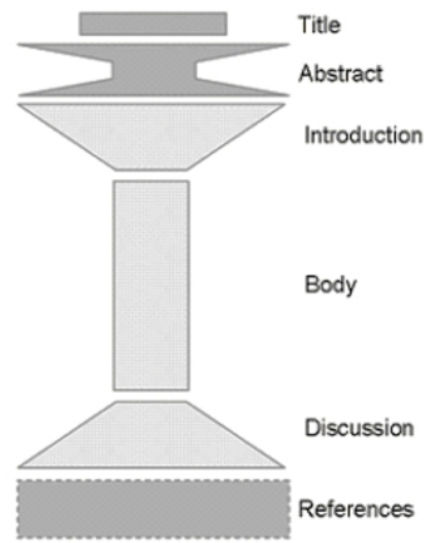

Figure 2. The 'King Model', which covers an extended set of parts in a typical paper's structure (Source: Based on Swales, 1993)

\section{a. Title}

It is the part of paper which is usually read most often. The title of the paper should be specific, accurate and complete. It should begin with the subject of the paper and should comprise the main identity of the paper. It should not contain any abbreviations unless it is well known by target audience and should attract the readers. It should be less than 15 words and should include the key results of the research.

\section{b. Abstract}

It is the summary of whole research paper. It should be in format of mini IMRD (Introduction, Methods, Results and Discussion). It should not be more than required and as indicated in the instructions of the journal. It addresses the objective of the paper. It describes the material and methods of research paper, its results and conclusion. It is just a summary of the paper so it cannot be substituted as full paper.

\section{c. Introduction/Background}

The introduction parts provide the general motivation and broad subject to a particular research question which is described in the main body of the research paper. It describes the importance of the subject. It should include considerable amount of general information and should be specific. It should explain the question addressed by the researcher. The author should explain the rationale and background to the study in this section. It should also mention the constructive suggestions for improvement of the research article.

\section{d. Body}

The body of the paper remains within the scope of the research paper and describes the materials and methods and results in detail including statistical methods used. It provides arguments and evidence to support the research paper. It consists of methods, result section.

Methods - it should provide readers with sufficient details about study method, should be specific, concrete, technical and detailed. It should mention study setting, sampling used, instruments, data collection, and analysis strategy.

Results-should include all the important finding of the research in table/figure form. It should describe participants demographic and clinical conditions.

\section{e. Discussion}

The discussion is the important part of research paper. It mainly focuses on how the results approve or disapprove the hypothesis. The result obtained from the research should be explained and compared with the findings of other research which have been done previously. The structure of discussion should be in accordance to the research question, hypothesis and result. In the discussion part, evaluation, interpretation and implication of the result are needed. The shortcomings and limitations can be explained in this part.

\section{f. Conclusion}

In the conclusion section, one can write the main result of the research paper. Implications based on the findings are important here and new research question can be named. But no new ideas are introduced in the conclusion part.

\section{g. Reference}

It is the essential part of research writing. When some source is used for ideas or information for the research work, one must acknowledge the source. The main purpose of reference is to enable the reader to check what sources of information have been used in the research. It helps the reader to locate the particular source of information.

\section{i. Referencing style}

There are various standard methods used for citing the source of work. These methods are called as referencing styles or citation styles. Citations may be parenthetical references, footnotes or endnotes.

Different publishers require different formats or styles for citing a paper in the text and for listing references. The citation or referencing style depends on the discipline on which the articles are written for. The referencing system is broadly divided into two types: a) Author date (parenthetical) system b) Notation system.

a) Author date system: It includes the author and date of publication, hence named as author date system.

b) Notation system: In this system, a superscript number (e.g. 1) is placed in the text. This number refers the reader to a footnote or endnote. This system is traditionally used in arts and humanities, and sometimes in social science. This system is also used in biomedical disciplines (e.g. in Vancouver style). ${ }^{10}$ 
The common citation styles are:

A) APA style (American Psychological Association): Commonly used for social science.

B) MLA style (Modern Language Association): Commonly used in humanities.

C) Chicago manual style (CMS): Commonly used in history and fine arts discipline

D) Harvard style: author date system is commonly used in Harvard style of referencing. All the information is included in this list. Author, date, title of publication, publisher and where it was published. ${ }^{11}$ E.g. Hasler, E 2018, The built environment, Liverpool University Press, Liverpool (or) Edwards, I.R. and Aronson, J.K., 2000. Adverse drug reactions: definitions, diagnosis, and management. The Lancet, 356(9237), pp.12551259.

E) Vancouver style: it is a numbered referencing style commonly used in medicine and science. It uses either bracketed or superscript number in the text, which connects with list of references at the end of the work. The same number can recur, e.g. If a source is mentioned more than once in the text. $^{12}$ E.g. Edwards IR, Aronson JK. Adverse drug reactions: definitions, diagnosis, and management. The Lancet. 2000 Oct 7;356(9237):1255-9.

\section{WRITING FINAL DRAFT}

In this stage, revision and editing of the article is needed to make the article better. While writing final draft, one can delete, add, replace, move words, sentence and passage in the text. Sufficient time should be given for revision of the research work. The final draft of the research paper is presented in word processed format and includes 12 sized font texts, doubled space, one-inch margin on all sides. The citation page should be typed on a separate sheet of paper.

\section{REFERENCES}

1. Guide to writing research paper. Germanna community collegeacademic center for excellence 2016;pg 423-9148.

2. Gibaldi J, Achtert WS, Modern Language Association of America. MLA handbook for writers of research papers. New York: Modern Language Association of America; 2003 May.

3. Hoogenboom BJ, Manske RC. How to write a scientific article? International Journal of Sports Physical Therapy. 2012 Oct;7(5):512.

4. Bhakar SS, S. Tarika. "A Handbook for writing research paper" Bharti publication, Delhi (India) $1^{\text {st }}$ edition, 2014; 1-178.
5. Perneger TV, Hudelson PM. Writing a research article: advice to beginners. International Journal for Quality in Health Care. 2004 Jun;16(3):191-2.

6. Guide to writing research paper. Mount Saint Vincent University Library. http://www/,svi/ca/site/media/msvu/howtowrite. researchpaper2

7. Kallestinova ED. How to write your first research paper? The Yale Journal of Biology and Medicine. 2011 Sep;84(3):181. Derntl M. Basics of research paper writing and publishing. International Journal of Technology Enhanced Learning. 2014 Jan;6(2):105-23.

8. Lester JD, Lester JD. Writing research papers: A complete guide. Pearson; 2012.

9. Basic principles of referencing. Lincon University 2013.https://library2.lincoln.ac.nz/documents/Referencing Why When How.pdf

10. MH.Alvi. A Manual for referencing styles in research. 2016.

11. Neville C. Referencing: principles, practice and problems. RGUHS. J Pharm Sci. 2012 Apr;2(2):1-8.

12. Neville C. The complete guide to referencing and avoiding plagiarism. McGraw-Hill Education(UK); $2010 \mathrm{Feb}$. 